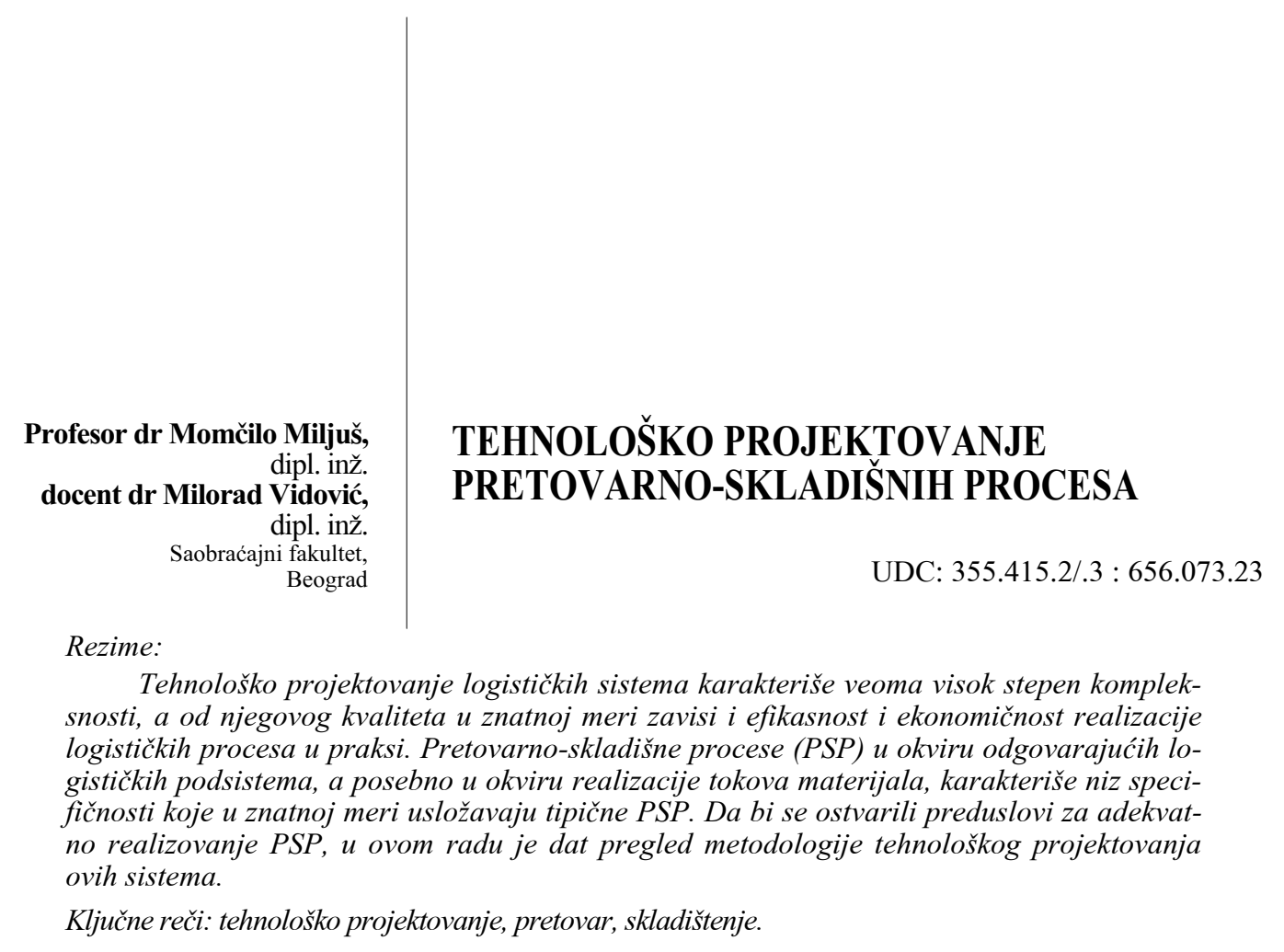

\title{
TECHNOLOGICAL DESIGN OF LOADING/UNLOADING AND WAREHOUSING PROCESSES
}

Summary:

Design of technological processes is one of the most complex tasks in the field of design in general. This type of design is also involved in logistic system design as these systems are typically very complex so that quality of design solution has a great influence on efficiency and economical level of logistic processes efficiency in practice. Loading/unloading and warehousing processes (LUWP) within some logistics systems, especially in material flows, require specific efforts which complicate typical LUWP. Aiming to consider adequate realisation of LUWP, this paper shows the methodology of design of these systems.

Key words: technological design, loading/unloading, warehousing.

\section{Uvod}

Transport roba danas dobija sve značajnije mesto u okviru zadataka koji se postavljaju pred društvenu reprodukciju uopšte. Međutim, realizacija zadataka $\mathrm{u}$ oblasti transporta vremenom postaje sve složenija, jer se, pored zahteva za sve većim stepenom racionalizacije transportnih lanaca, jednovremeno intenziviraju i generišu sve složeniji zahtevi u domenu bezbednosti, ekologije i nekim drugim oblastima značajnim za procese $u$ društvu.
Zbog ovakvih uslova, problematici realizacije tokova materijala, treba, s obzirom na izuzetnu kompleksnost faktora koja utiče na njihovu efektivnost, pristupiti na odgovarajući način, odnosno na osnovu logističkih principa. Ovi principi nameću, pre svega, sistemski pristup još u fazi projektovanja navedenih procesa, kako bi se još na tom nivou ostvarili preduslovi za realizaciju svih aktivnosti u okviru transportnih lanaca na željenom nivou, uz respektovanje, kako je naglašeno, sve složenijih zahteva (i ograničenja) po nizu kriterijuma. Kako u okviru tran- 
sportnih lanaca pretovarno-skladišni procesi (PSP) imaju posebno mesto, u ovom radu ukazano je na metodologiju tehnološkog projektovanja sistema za njihovu realizaciju.

U literaturi je ovoj oblasti, zbog njenog značaja, još pre nekoliko decenija počela da se posvećuje sve veća pažnja. Tako, na primer, sve više se naglašava povećanje interesa, kako o projektovanju sistema za rukovanje materijalima, tako i za njihovo funkcionisanje [1]. Hijerarhijski, projektovanje je obuhvaćeno strateškim, a funkcionisanje taktičkim aspektom, pri čemu se naglašava da je zbog spektra zadataka i kompleksnosti procesa veoma teška sama formulacija problema i optimizacije u procesu tehnološkog projektovanja. U praksi su se iznalazila rešenja različitog kvaliteta, primenom iskustvenih metoda (tzv. „rule-of-thumb“ i heuristika). Ratliff i Nulty [2], takođe, ukazuju na kompleksnost tehnološkog projektovanja koje nameće respektovanje niza relevantnih aspekata sistema i okruženja pri projektovanju i donošenju odluka. To se potvrđuje i u [3], što ukazuje na to da se i pri samom skladištenju sreće veoma složena problematika vezana za njegovo projektovanje (sa težištem na intenzitetu protoka roba kroz skladište, kapacitetu skladišta i obliku samog skladišnog objekta) kao polaznim faktorima. Jedan od pristupa u domenu problematike rukovanja materijalima, sa sekvencijalno datim aktivnostima (bez njihove međuzavisnosti), prikazan je u [4].

Može se konstatovati da korektan pristup ovom projektovanju zahteva primenu načela sistemskog pristupa i tehnika agregacije i disagregacije u procesu razvoja rešenja (slika 1). Shodno tome, ovaj rad je obuhvatio prikaz karakterističnih faza prisutnih u tehnološkom projektovanju, i to:

- analizu mesta i uloge PSP;

- definisanje zadataka koji se postavljaju pred pretovarno-skladišni sistem (PSS);

- razvoj varijanti strukture PSS i tehnologija realizacije PSP;

- izbor optimalnog iz skupa varijantnih tehnoloških rešenja.

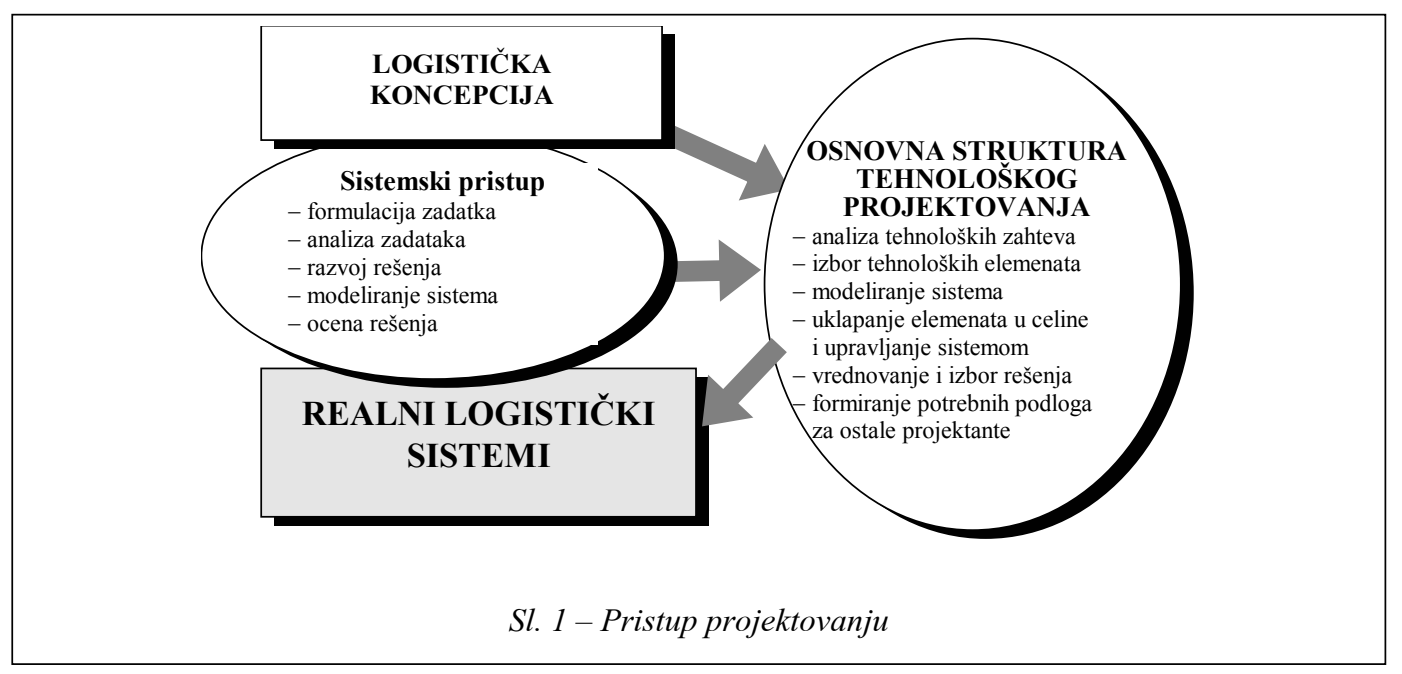




\section{Mesto i uloga pretovarno- -skladišnih procesa}

Veza između transporta, privrede i drugih delatnosti u kojima se realizuju tokovi materijala (slika 2) fundamentalna je. Transport, kroz ispunjavanje različitih zadataka, obezbeđuje integraciju privrede, pri čemu njegovi troškovi $u$ znatnoj meri utiču na vrednost robe i efektivnost procesa reprodukcije. Pri tome, ne može se zanemariti učešće transportne privrede $u$ društvenom proizvodu, kao i angažovanju resursa. Nadalje, povećanje standarda i zadovoljenje ostalih društvenih ciljeva uslovljava ostvarenje adekvatne podele rada između pojedinih vidova transporta, pri čemu taj zadatak, pored niza kvantitativnih, sadrži i niz kvalitativnih karakteristika.

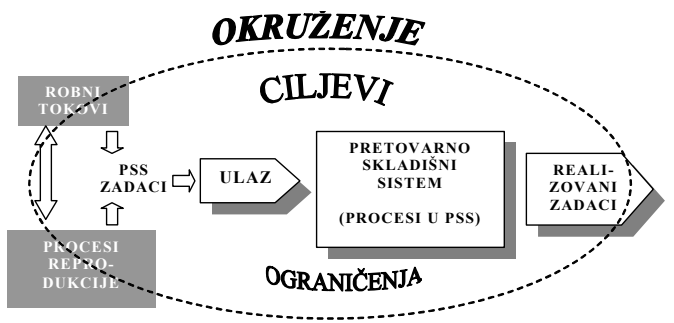

Sl. 2 - Osnovni odnos procesa reprodukcije, robnih tokova i PSP

Razvoj transportnih tehnologija, a time i PSP kao njihovih činilaca, usmeren je ka snižavanju troškova transporta, po mogućnosti kod svih učesnika u transportnom lancu, ali i sa stanovišta celokupne privrede i šire. Da bi se to ostvarilo, kao prioritetni ciljevi mogu da se izdvoje: odgovarajuća distribucija roba (pre svega sa vremenskog aspekta dostave), smanjenje potrošnje vitalnih sirovina i resursa, postizanje zahtevanog nivoa zaštite ljudi, materijalnih dobara i život- nog okruženja, povećanje materijalnih bogatstava, poboljšanje saobraćajnih uslova i dr. (slika 2). Pri tome, PSP ne pripada strogo ni jednom od klasičnih vidova transporta - oni mogu biti sadržani unutar pojedinih vidova ili, što je tipično, na mestima povezivanja različitih vidova transporta. Takođe, u znatnoj meri prisutni su, odnosno sadržani, i u oblasti industrijskog transporta u okviru proizvodnih sistema.

Imajući to u vidu, PSP u okviru društvene reprodukcije imaju ulogu da $u$ okviru transportnih lanaca omoguće realizaciju nekoliko osnovnih funkcija:

- prostorno izjednačavanje, kada se transportnim lancima spajaju prostorno razdvojena mesta proizvodnje i potrošnje. Tada, ukoliko se realizuje skladištenje, dolazi do privremenog prekida transportnog procesa;

- vremensko i kvantitativno izjednačavanje, kada se javlja vremenska i kvantitativna neusaglašenost $\mathrm{u}$ procesu kretanja robe. Može biti posledica vremenski nesinhronizovanih intenziteta proizvodnje i potrošnje, kretanja i tehnoeksploatacionih parametara transportnih sredstava u transportnim lancima i dr.;

- izjednačavanje asortimana, kao zahtev koji nastaje usled neusaglašenosti formiranja asortimana po mestu ili vremenu nastanka u okviru proizvodnog sistema $\mathrm{u}$ odnosu na zahteve potrošnje (bilo $u$ okviru proizvodnih podsistema ili tržišta).

Uprošćeno predstavljeno, makrostruktura transportnog lanca u sferi kretanja roba može se predstaviti kao na slici 3. Na svim mestima sučeljavanja različitih sistema koje povezuje transportni lanac, pojavljuje se i PSS. 


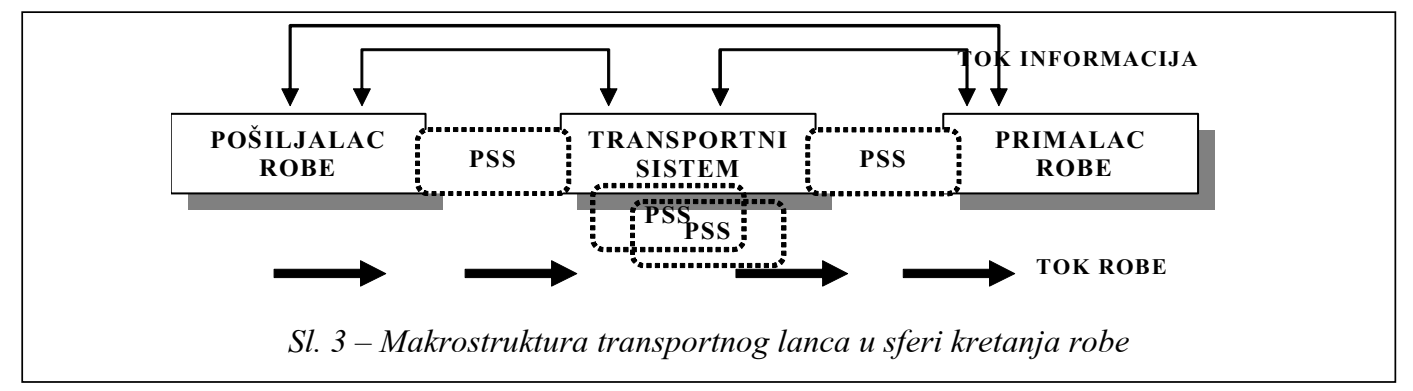

\section{Definisanje zadataka pretovarno-skladišnog sistema}

Sagledavanjem mesta i uloge PSS uočava se da on u okviru transportnih lanaca ima značajan uticaj na kvalitet funkcionisanja. Drugim rečima, zadaci koji se generišu postavljanjem ciljeva šireg okruženja generišu funkcionisanje PSS, koji na odgovarajući način postaje „aktivan“ i teži da realizuje postavljene zadatke, odnosno da deluje na okruženje. Imajući to u vidu, osnovna karakteristika PPS je da u okviru njega egzistiraju tehnološki zahtevi, i da se realizuju postavljeni tehnološki zahtevi angažovanjem odgovarajućih resursa i organizacijom.

Tehnološki zahtevi koje obuhvata zadatak PSS prevashodno zavise od uloge, odnosno sistema koje povezuje u transportnom lancu [5]. Ne ulazeći u niz mogućih kombinacija, u praksi se obično sreću sledeći osnovni tehnološki zahtevi u PSP:

- istovar transportnog sredstva (ili izlaz iz procesa proizvodnje),

- transport od mesta istovara do mesta skladištenja (odlaganja),

- uskladištenje robe,

- čuvanje robe,

- iskladištenje (zahvatanje),

- transport do mesta utovara,
- utovar u transportno sredstvo (ili ulaz u dalji proces proizvodnje).

Pored ovih osnovnih zahteva, PSP često obuhvataju i niz drugih zahteva (sortiranje, kondicioniranje, komisioniranje, prepakivanje i dr.). Ne treba posebno ukazivati na to da zbog jake veze skupa tehnoloških zahteva i PSS koji treba da ih realizuje, efikasnost realizacije PSP izuzetno zavisi od nivoa usaglašenosti pretovarnog zadatka (skupa tehnoloških zahteva) i PSP, sa jedne, i od karakteristika sistema na višem hijerarhijskom nivou (transportnih lanaca) koje PSS opslužuje, sa druge strane.

Da bi se omogućilo kvalitetno tehnološko projektovanje, $\mathrm{u}$ konkretnom problemu značajno je da se tehnološki zahtevi (TZ) na adekvatan način identifikuju i opišu. Identifikacija je vezana sa raščlanjivanjem osnovnog zadatka do nivoa koji obezbeđuje sagledavanje relevantnih veza između njih i elemenata koji ih realizuju. Pri tome se ukazuje da je ovako definisan TZ po pravilu višedimenzionalan, i da je opisivanje njegovih relevantnih parametara složeno. U takvoj situaciji, potrebno je da se TZ korektno prikažu kroz sagledavanje značajnih karakteristika i njihovo opisivanje. Kako one $u$ znatnoj meri mogu da odstupaju i od jednog do drugog TZ i između konkretnih PSP, tome treba posvetiti poseb- 
nu pažnju. U praksi su, najčešće, za opisivanje u okviru PSP najznačajnije sledeće karakteristike TZ: pojavni oblik (količina), mesto nastanka - završetka u prostoru, vreme (zakon nastanka) i realizacije (za poznate tehnologije), interval strpljivosti i dr. Međutim, ove karakteristike se u praksi mogu bitno razlikovati i kod istih TZ, pa je radi bližeg opisivanja neophodno utvrditi i obeležja karakteristika TZ. U PSP se kao potencijalna obeležja karakteristika TZ pojavljuju:

- determinističnosti ili stohastičnosti,

- stacionarnosti ili nestacionarnosti,

- homogenosti ili nehomogenosti,

- kontinualnosti ili diskontinualnosti.

Treba naglasiti da karakteristike TZ mogu da imaju različite kombinacije navedenih obeležja. Ovaj spektar može biti od (uslovno povoljne) kombinacije obeležja determinističnosti, stacionarnosti, homogenosti i kontinualnosti, pa do (po pravilu nepovoljne) kombinacije stohastičnosti, nestacionarnosti, nehomogenosti i diskontinualnosti. Svaka od kombinacija ima specifičan uticaj na pojedine korake u daljim fazama projektovanja, tako da je istraživanje mogućnosti uticaja na karakteristike TZ i njihova obeležja (i efekata tih uticaja na PSP) od posebnog značaja.

Ako se obeležja identifikovanih relevantnih karakteristika TZ odlično poznaju može se smatrati da je zadatak PSS moguće opisati na kvalitetan način (slika 4). Drugim rečima, tek na osnovu raspolaganja tim informacijama moguće je kvalifikovano pristupiti daljem tehnološkom projektovanju PSP. To posebno dobija na značaju u okviru PSP, vezanim za snabdevanje vojnih jedinica, jer nepoznavanje ili nerespektovanje posebnih

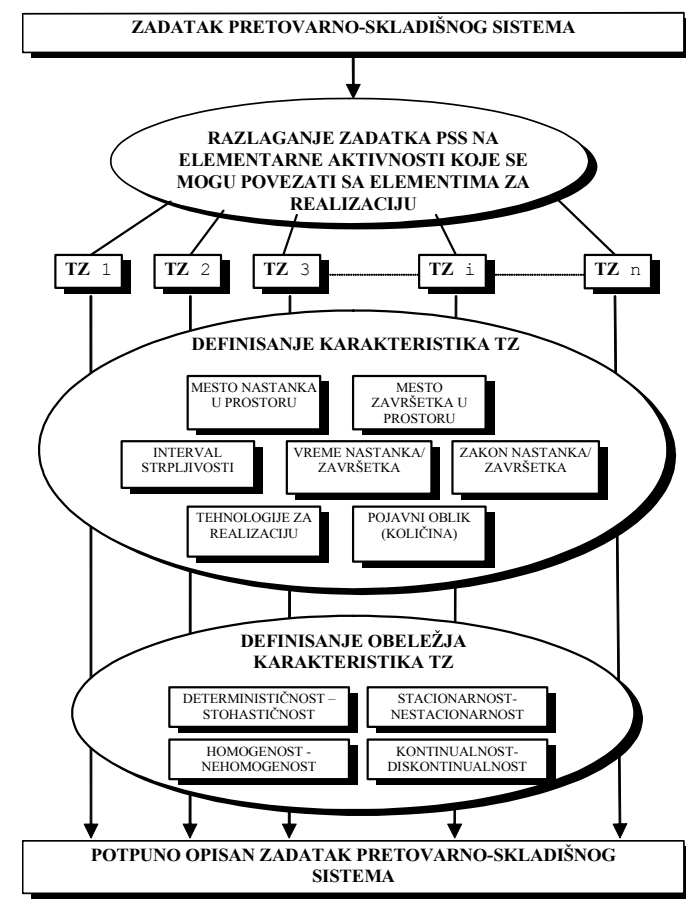

Sl. 4 - Opisivanje PS zadatka

specifičnosti TZ, njihovih karakteristika i obeležja (strukture i osobina robe, uslova realizacije procesa u ratu ili miru, strategije zaliha i njihovog lociranja, tehnoeksploatacionih parametara tehnoloških elemenata itd.) može u bitnoj meri da degradira servis-stepen, ili čak onemogući realizaciju logističkih funkcija sa svim posledicama koje iz takvog stanja mogu da proisteknu.

\section{Razvoj varijanti strukture pretovarno-skladišnih sistema i tehnologije realizacije pretovarno-skladišnih procesa}

Nakon definisanja mesta i uloge i definisanja zadataka koji se postavljaju pred PSS, pristupa se razvoju varijantnih tehnoloških rešenja PSP. Ovaj razvoj 
pretpostavlja nekoliko koraka: definisanje tipičnih tehnologija, razvoj varijantnih tehnoloških koncepcija i tehnoloških rešenja.

\section{Tipične - atipične tehnologije}

U procesu tehnološkog projektovanja neophodno je ukazati i na značaj međusobne veze $\mathrm{TZ}$ - tehnološki element (TE) koji taj zahtev izvršava. Moguće polje stanja ovog odnosa je takvo da korišćenje jednog TE može da utiče na primenu strogo određenog TE (ili grupe TE) za realizaciju nekog drugog TZ. Takođe, moguće su uzročno-posledične veze između pojedinih $\mathrm{TZ}$, tako da se u polju stanja teži grupisanju TZ u skupove koji su homogeni sa aspekta realizacije. Ovakvom skupu, odnosno grupi TZ (TG), koji čini jednu tehnološku celinu u okviru PSS može se „dodeliti““ jedinstveni način izvršavanja, koji se, zavisno od primenjenosti u praksi, naziva tipična ili atipična tehnologija (TT/AT). Razvoj nauke i tehnike omogućio je da se grupe TZ mogu izvršavati na različite načine, tako da se svakoj grupi može dodeliti i različiti skup TT/AT.

Radi daljeg projektovanja neophodno je da se TT/AT potpuno definišu, što se postiže ako su utvrđeni:

- struktura TZ u okviru PSP sa svojim relevantnim karakteristikama i obeležjima,

- struktura primenjenih TE i njihovom vezom sa $\mathrm{TZ}$,

- rešenja mikrolokacije koja su povezana sa realizacijom procesa $u$ okviru TT/AT,

- postupci operativnog upravljanja pri realizaciji $\mathrm{TZ}$.
Struktura TE i njihova veza sa TE treba tačno da definiše koji(e) TZ realizuje(u) TE, što pretpostavlja poznavanje preciznih tehno-eksploatacionih karakteristika TE. Zbog mogućih različitih kombinacija, za sagledavanje odnosa TZ/TE u okviru TT može se primeniti matrica odnosa TZ/TE. Kako je veoma širok spektar TZ koji se sreću u praksi, kod PSP na tržištu je prisutna izuzetno velika ponuda opreme, sa različitim nivoima kompleksnosti, proizvodnosti, fleksibilnosti i dr., sa ciljem da se njima realizuju TG. To ukazuje da se TG mogu realizovati na više načina, što je principijelno predstavljeno na slici 5.

Rešenja mikrolokacije u okviru TT obično su vezana za rešavanje problema layouta, tako da je neophodno da se utvrde svi neophodni zahtevi za prostorom predviđenih TE, kao i sam razmeštaj TE u prostoru. Ovaj korak je neophodno realizovati u okviru TT/AT, kako bi se znao ambijent realizacije PSP, trajektorije tokova materijala, mobilne opreme, angažovani prostor i dr., što je od posebnog

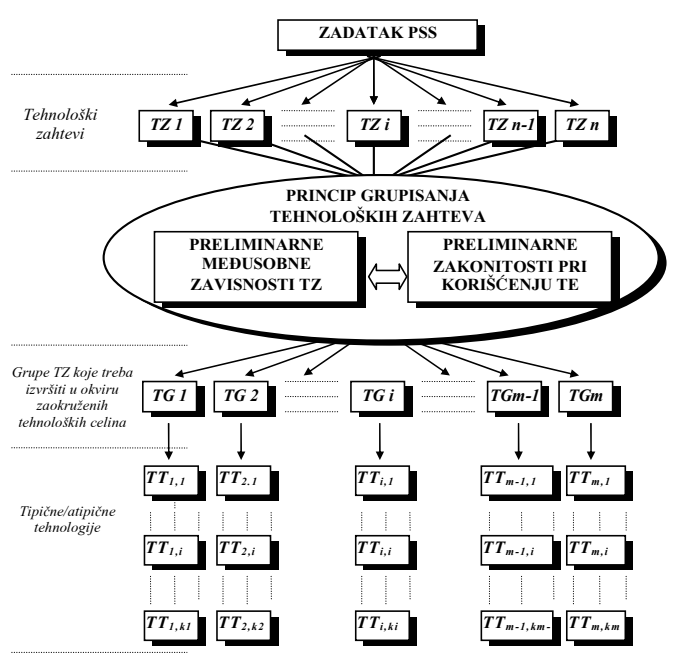

Sl. 5 - Principi uobličavanja TT 
značaja za dalje projektovanje i primenu odgovarajućeg tehnološkog rešenja.

Upravljanje u okviru TT/AT ima poseban značaj, jer se njime, u okviru TT/AT (primenjenih za PSP), utvrđuju skupovi i redosledi aktivnosti (u prostoru raspoređenih) TE pri realizaciji sa njima povezanih TZ. Nivo kvaliteta upravljanja direktno utiče na ostvarivanje tehno-eksploatacionih karakteristika TE, a time i na nivo kvaliteta funkcionisanja celog PSS.

\section{Razvoj tehnoloških koncepcija}

U prethodnom koraku se formira skup varijantnih TT/AT za tehnološku celinu (odnosno TG). Ne treba naglašavati da same TT/AT za sebe ne predstavljaju tehnološko rešenje koje se ad hok može primeniti u PSS. Radi toga je neophodno formirati skup TT/AT kojima su obuhvaćeni svi TZ, a koji može biti primenjen na ceo PSS (slika 6). Jedan takav tehnološki usklađen skup TT/AT je varijantna tehnološka koncepcija (TK).

Kao što se može zaključiti, pri angažovanju više TT/AT pri realizaciji tokova materijala u PSS one međusobno treba da budu kompatibilne. Na primer, tehnologija primenjena na frontu pretovara mora biti usaglašena sa tehnologijom uskladištenja - iskladištenja ukoliko su one u direktnoj vezi. Spektar situacija u praksi je takav da se sreću rešenja gde se sredstva za istovar - utovar koriste i za uskladištenje - iskladištenje robe. Nasuprot tome, sreću se situacije da pojedine TT/AT mogu biti potpuno nezavisne od drugih, pa se pri razvoju rešenja u okviru njih ne mora $u$ istoj meri voditi računa $o$ rešenjima $u$ ostalim delovima PSS (na primer, neka od faza međupogonskog transporta $\mathrm{u}$ proizvodnom procesu). Iz ovih razloga TT/AT u okviru jedne TG mogu da budu zavisne i nezavisne od tehnološke koncepcije. U ovakvim uslovima jedna varijantna TK predstavlja skup koji se sastoji od dva podskupa podskupa TT/AT koje zavise od TK i podskupa TT/AT koje ne zavise od TK.

Neophodno je naglasiti da izbor i grupisanje TT/AT koji čine jednu TK nije dovoljno za njeno potpuno opisivanje već je neophodno definisati rešenja vezana za oblast upravljanja i korišćenja prostora, ali za sve TT/AT u okviru TK. Ne

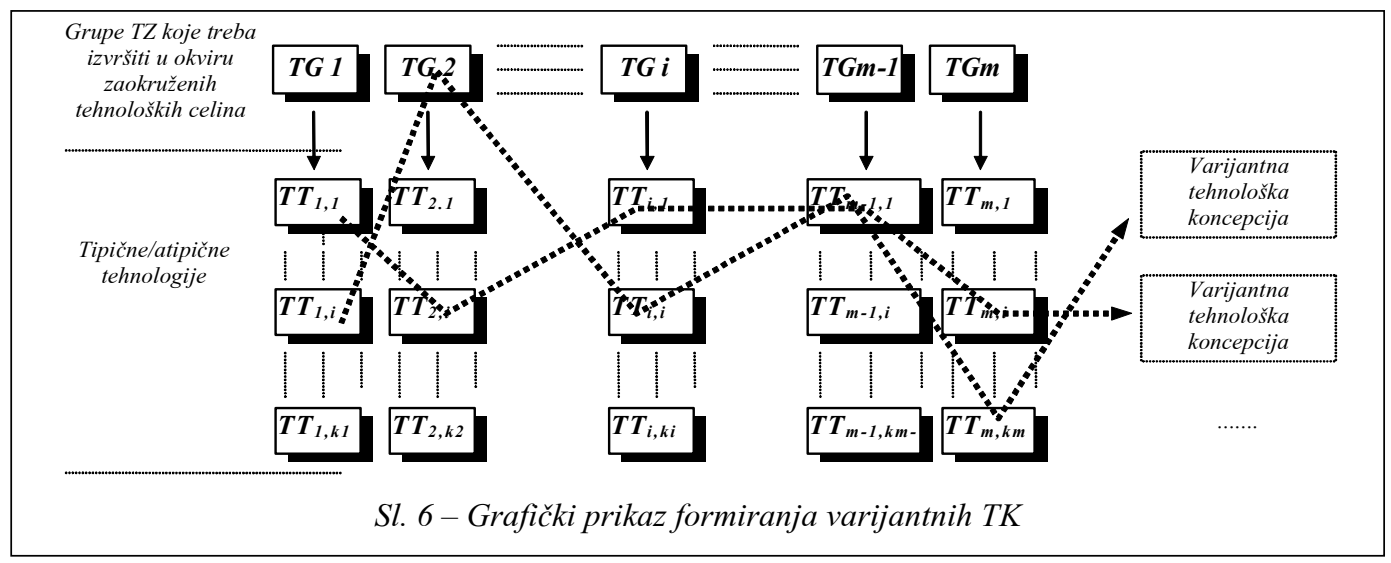




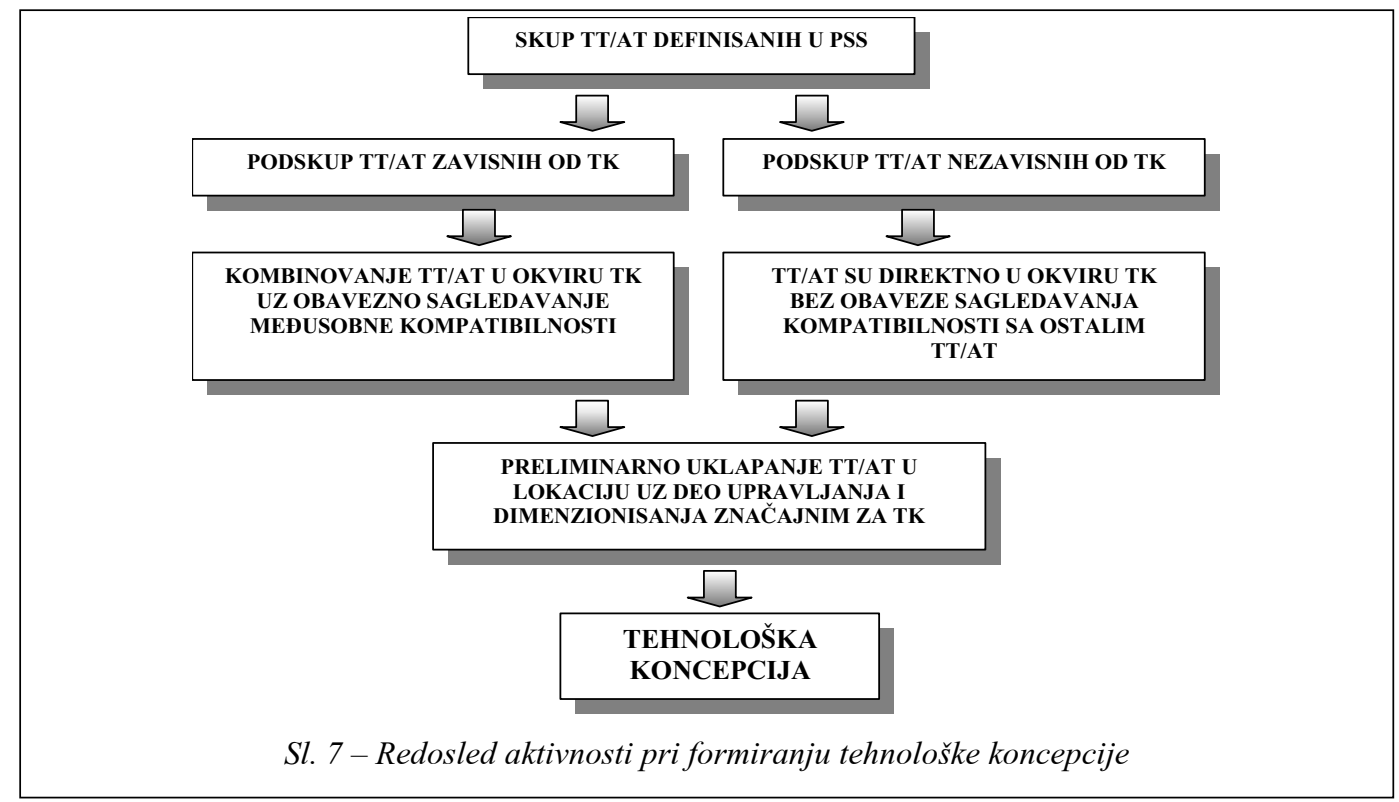

treba posebno naglašavati da je potrebno sve TK predviđene TT/AT preliminarno locirati na raspoloživom prostoru. U tom koraku projektovanja nije retka situacija da ograničenja lokacije isključe neku TK iz skupa varijantnih TK. Nadalje, preliminarno prostorno raspoređivanje omogućava definisanje nekih karakteristika TZ, pre svega mesta nastanka - završetka realizacije TZ.

Radi ostvarivanja zadatka PSS sve TT/AT, u okviru jedne TK, moraju da funkcionišu u zajedničkom PSS. Zbog toga je neophodno formiranje zajedničkog rešenja upravljanja PSP koji tačno definišu odnose TZ/TE. Kako upravljanje nije nezavisno od strukture TE, neophodno je obaviti i njihovo preliminarno dimenzionisanje u okviru varijantne TK (uz respektovanje relevantnih faktora, kao što su prioriteti, uslovi realizacije TZ i dr.).

Redosled prethodno opisanih koraka grafički je predstavljen na slici 7.

\section{Tehnološko rešenje}

Tehnološka rešenja (TR), pojednostavljeno rečeno, nastaju daljom nadgradnjom TK. Shodno izloženome, za skup varijantnih TK, koje su realno ostvarljive, moguće je razviti skup varijantnih TR. „Prerastanje“ TK u TR ostvaruje se kroz niz aktivnosti, po pravilu na veoma detaljnom nivou, $u$ oblasti modeliranja sistema, kvantifikovanja TE, njihovog uklapanja u lokaciju (na makro i mikronivou, povezivanja sa javnim saobraćajem i sl.), detalje vezane za procese upravljanja (eventualno uz izbor konkretnog softvera i hardvera).

Posebno je značajno da se u okviru razvoja varijantnog TR formiraju podloge, odnosno zahtevi za ostale projektante, čime se u potpunosti koncipira PSS. Ove podloge su potrebne za oblasti projektovanja visokogradnje, niskogradnje, urbanizma, raznih instalacija, fluida, in- 
formacionih sistema, protivpožarne zaštite, zaštite na radu i fizičko-tehničkog obezbeđenja.

\section{Izbor tehnološkog rešenja}

Iz skupa varijantnih rešenja potrebno je izabrati najbolje, što zahteva donošenje odluke o najpovoljnijem tehnološkom rešenju. To nije jednostavno uraditi. U ovoj fazi, kada su formirana varijantna TR (sa usaglašenim kvalitetom realizacije PSP), potrebno je primeniti metodologiju za njihovo vrednovanje, pri čemu treba jednovremeno da se respektuju postavljeni ciljevi, ograničenja i kriterijumi koji u okviru modela treba da se primene. Ne ulazeći u moguće pristupe i modele vrednovanja, može se reći da ne postoji egzaktno pravilo koji postupak treba da bude primenjen u konkretnom slučaju. Jer, u nekim slučajevima su dominantna investiciona ograničenja, nekada servis-stepen realizacije PSP, bezbednost, uticaj na okruženje i dr., kao i potencijalne kombinacije ovih kriterijuma.

Po izboru optimalnog tehnološkog rešenja PSP ono predstavlja deo projekt- ne dokumentacije koja se koristi za sve dalje faze rada, od projektnog zadatka, idejnog projekta do glavnih tehnoloških projekata (slika 8).

\section{Zaključak}

U radu je na sažet način predstavljena veoma kompleksna oblast tehnološkog projektovanja jedne klase logističkih procesa (pretovarno-skladišnih procesa). Ukazano je na tipične korake ovog projektovanja, kao i specifičnosti koje posebno moraju dodatno da se analiziraju i respektuju pri tehnološkom projektovanju PSP pri realizaciji tokova materijala za potrebe vojnih jedinica. Naglašava se da odstupanje od pojedinih koraka i aktivnosti pri tehnološkom projektovanju, primenjivanje neodgovarajućih modela $\mathrm{i}$ postupaka neminovno dovodi do rešenja koja u kasnijem radu neće zadovoljiti postavljene zahteve, a nekada mogu i da u potpunosti onemoguće realizaciju PSP. Predstavljena metodologija projektovanja u znatnoj meri je proistekla i kao rezultat iskustava konkretnih studija i projekata, koji su za potrebe JNA i privrede

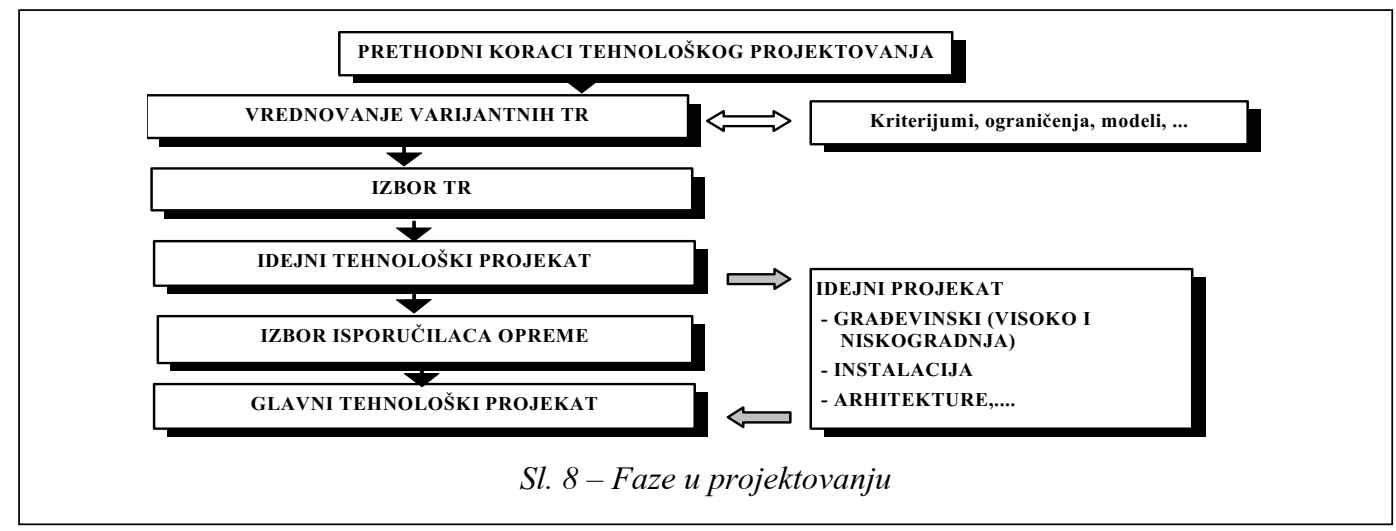


u dužem periodu realizovani na Odseku za logistiku Saobraćajnog fakulteta u Beogradu.

Literatura:

[1] Matson, O. J.; White, J. A.: Operational research and material handling, European Journal of Operational Research, 11 (1982).

[2] Ratliff, H. D.; Nulty, W. G.: Logistics composite modeling, Technical White Paper Series, The Logistics Institute at Georgia Tech, 1996

[3] Cormier, G.: A review of warehouse models, European Journal of Operational Research 58, 1992.
[4] Kulwiec, R.: Considerations for planning and implementing integrated material handling systems, Material Handling Industry of America, ISC/MHIA Publication.

[5] Vukićević, S.: Skladišta, Preving, 1995, Beograd.

[6] Sretenović, M.: Mehanizacija pretovara, Univerzitet u Beogradu, 1966.

[7] Vukićević, S.; Sretenović, M.; Vidović, M.: Tehnološko projektovanje novih skladišta za UbS, Tematski skup „Kvalitet uskladištenih UbS“, 1994, Beograd.

[8] Vukićević, S.; Miljuš, M.: Predlog postupaka za optimizaciju strukture objekata novog skladišta za zadatu količinu UbS, Tematski skup „Kvalitet uskladištenih UbS“, 1994, Beograd.

[9] Sharp, G., et all.: A Structured Approach to Material Handling System Selection and Specification for Manufacturing, Working Paper. 